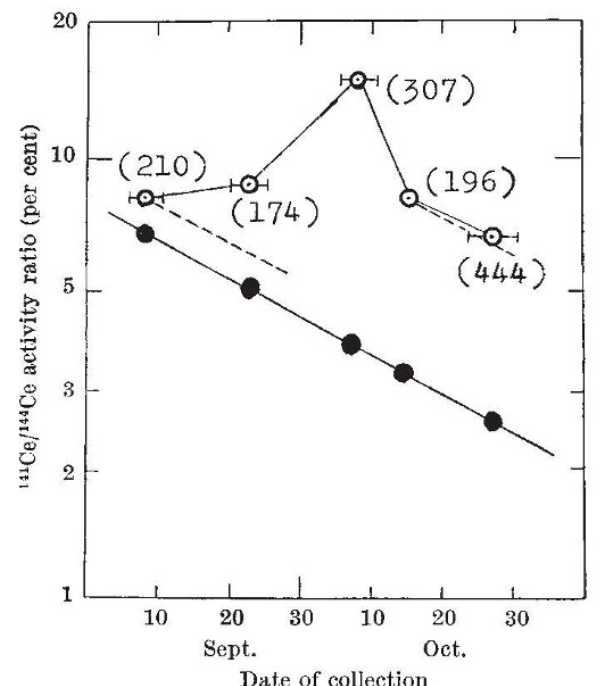
Fig. 1. Cerium-141: 144 activity ratios in rain samples between Septem-
ber and October 1968 . Points $\odot$ give the ${ }^{141} \mathrm{Ce} / 14 \mathrm{Ce}$ ratio. Broken lines show the curves expected from the characteristic decays of the two cerium isotopes. The solid line (- - ) is drawn on the assumption that the two cerium isotopes with the same fission yield of 6.0 originated oniy from the latest Chinese nuclear test on December 28, 1967. Figures in parentheses indicate a sample volume $(l)$ of each combined rain sample.

speed of $\sim 12 \mathrm{~km} / \mathrm{h}$. This is comparable with the mean speed of those typhoons which visited Japan between August and September. The present observations on the interhemispheric transfer of radioactivities through the troposphere suggest that airborne material can travel from the southern to the northern hemispheres at a speed of several meters per second between late summer and early autumn.

Department of Chemistry,

\section{TAkeshi Sotobayashr} Toshio SUzukI

Department of Physies,

\section{Akira Furusawa}

University of Niigata,

Niigata, Japan.

Received July 25; revised September 12, 1969.

1 Kuroda, P. K., Miyake, Y., and Nemoto, J., Science, 150, 1289 (1965).

'Thein, M., and Kuroda, P. K., J. Geophys. Res., 72, 1673 (1967).

Sotobayashi, T., Suzuki, T., and Koyama, S., Bull. Chem. Soc. Japan, 42, 716 (1969).

4 Koyama, S., Sotobayashi, T., and Suzuki, T., Nature, 209, 239 (1966).

\section{Sodium Distribution in the Terrestrial Upper Atmosphere}

Onservations ${ }^{1-3}$ of the twilight glow and dayglow have shown that there is a thin layer of free sodium atoms at a height of about $90 \mathrm{~km}$. There is usually a daytime enhancement of the sodium abundance compared with the abundance at twilight; the daytime layer seems to be at the same height or a few kilometres higher than the twilight layer. Furthermore, the scale heights on the topside (and on the bottomside) of the daytime layer are unoxpectedly small, ranging from $2.5 \mathrm{~km}$ (ref. 2) through $3 \mathrm{~km}$ (ref. 1) to $4.5 \mathrm{~km}$ (ref. 3), whereas the atmospheric scale height is about $6 \mathrm{~km}$.

These observations have led Donahue ${ }^{4}$ and Hunten and Wallace ${ }^{1}$ to suggest that the chemical theory alone is not adequate. The chemical theory, as developed, for example, by Blamont and Donahue ${ }^{5}$, predicts the sodium abundance to be determined by a balance between the oxidation reaction

$$
\mathrm{Na}+\mathrm{O}_{3} \rightarrow \mathrm{NaO}+\mathrm{O}_{2}
$$

and the reduction reaction

$$
\mathrm{NaO}+\mathrm{O} \rightarrow \mathrm{Na}+\mathrm{O}_{2}
$$

Blamont and Donahue ${ }^{5}$ estimate that the ratio of the number densities of $\mathrm{Na}$ and $\mathrm{NaO}$ is

$$
\frac{n(\mathrm{Na})}{n(\mathrm{NaO})} \bumpeq 6 \times \frac{n(\mathrm{O})}{n\left(\mathrm{O}_{3}\right)}
$$

Calculations of the atomic oxygen concentration ${ }^{6}$ and determinations of the ozone concentration ${ }^{7}$ show that in daytime $n(\mathrm{O}) / n\left(\mathrm{O}_{3}\right)$ is of the order of $10^{3}$ in the $85-95 \mathrm{~km}$ region. Relation (3) would then predict that $n(\mathrm{NaO})$ is negligibly small in this region.

Hanson and Donaldson ${ }^{8}$ have suggested an explanation of the small scale height to be found on the topside of the layer. In a steady-state situation upward transport of neutral sodium by eddy diffusion balances the loss at highor altitudes due to photoionization. There is a corresponding downward flux of sodium ions to the region of high recombination rate.

Several workers $1,2,4,9$ have suggested that release of atoms from dust particles or ablation of atoms from small meteors provides a thinly layered source of sodium around $90 \mathrm{~km}$, but Gadsden ${ }^{8}$ finds that sufficiont data do not exist to decide between these hypotheses. By solution of the steady-state continuity and momentum equations for sodium atoms and ions (details of which will be presented elsewhere) I have shown that the small, negative scale height on the bottomside of the layer is a consequence of the dust or meteoric source together with downward transport of sodium to the region of oxidation. The calculations give a maximum sodium concentration of about $3 \times 10^{4}$ atoms $\mathrm{cm}^{-3}$ when the source function has a maximum production rate of about 1 atom $\mathrm{cm}^{-3} \mathrm{~s}^{-1}$ and a half-width of $2 \mathrm{~km}$. With no sink for total sodium (atoms plus ions) above $90 \mathrm{~km}$ and $n\left(\mathrm{Na}^{+}\right)$of order 10 per cent of $n(\mathrm{Na})$, this sodium production function requires a downward flux of sodium of about $4 \times 10^{5}$ atoms $\mathrm{cm}^{-2} \mathrm{~s}^{-1}$ through the bottom of the layer. The flux $\varphi(\mathrm{Na})$ due to eddy transport is ${ }^{8}$

$$
\varphi(\mathrm{Na})=\operatorname{Dn}(\mathrm{Na})\left(\frac{1}{H}-\frac{1}{H_{0}}\right)
$$

where $D$ is the eddy diffusion coefficient, $H_{0}$ is the atmospheric scale height and

$$
H=-\left\{\frac{1}{n(\mathrm{Na})} \frac{\mathrm{d} n(\mathrm{~N} a)}{\mathrm{d} z}\right\}^{-1}
$$

where $z$ is altitude. With $H_{0}=6 \mathrm{~km}$ and taking $H$ as the measured $^{1}-3 \mathrm{~km}$ we find that

$$
\operatorname{Dn}(\mathrm{Na}) \simeq 8 \times 10^{10} \mathrm{~cm}^{-1} \mathrm{~s}^{-1}
$$

This value for the product $D n(\mathrm{Na})$ is reasonable. For example, if $n(\mathrm{Na})$ is $10^{4}$ or $2 \times 10^{4} \mathrm{~cm}^{-3}, D$ is about $8 \times 10^{6}$ or $4 \times 10^{6} \mathrm{~cm}^{2} \mathrm{~s}^{-1}$. These $D$ values are within the range deduced from oxygen transport calculations ${ }^{6}$ and investigation of instabilities in internal gravity waves ${ }^{10}$.

R. J. MOFFETT

Department of Applied Mathematics and

Computing Science,

University of Sheffield.

Sheffield S10 2TN.

Reccived October 30, 1969.

${ }^{1}$ Hunten, D. M., and Wallace, L., J. Geophys, Res., 72, 69 (1967).

${ }^{2}$ Donahue, T. M., and Meier, R. R., J. Qeophys. Res., 72, 2803 (1967).

${ }^{3}$ Gault, W. A., and Rundle, H. N., Canad. J. Phys., 47, 85 (1969).

4 Donahue, T. M., J. Geophys. Res., 71, 2237 (1966).

5 Blamont, J. E., and Donahue, T. M., J. Geophys. Res., 69, 4093 (1964).

Colegrove, F. D., Hanson, W. B., and Johnson, F. S., J. Geophys. Res., '70, 4931 (1965).

7 Evans, W. F. J., Hunten, D. M., Tlewellyn, E. J., and Vallance Jones, A., J. Geophys. Res., 73, 2885 (1968).

${ }^{8}$ Hanson, W. B., and Donaldson, J. S., J. Geophys. Res., 72, 5513 (1967).

${ }^{9}$ Gadsden, M., J. Atmos. Terr. Phys., 30, 151 (1968).

${ }^{10}$ Hodges, jun., R. R., J. Geophys. Res., 74, 4087 (1969). 